\title{
The Evaluation of Antioxidant Activity of Individual and Mixture of Lemongrass, Curry Leaves, Turmeric and Ginger Extracts
}

\author{
Kay Huck Poh, Norhayati Muhammad*, Norazlin Abdullah and Balkis A. Talip \\ Department of Technology and Natural Resources, Faculty of Applied Sciences and Technology, \\ Universiti Tun Hussein Onn Malaysia, Pagoh Educational Hub, 84600 Pagoh, Johor, Malaysia.
}

Received 30 September 2017; accepted 27 March 2018; available online 1 August 2018

DOI: https://10.30880/jst.2018.10.02.011

\begin{abstract}
Lemongrass (Cymbopogon citratus), curry leaves (Murrya koenigii), turmeric (Curcuma longa) and ginger (Zingiber officinale) are frequently used as ingredients in food industry. Recent researches proved these plants contain phytochemicals which contributes to antioxidant properties. However, the evaluation were done individually and rarely in mixtures. This study was conducted to examine the antioxidant properties as well as their interaction effect when mixed together. There were 18 designated formulations with various proportions obtained from Design Expert ${ }^{\circledR}$ 6.0.4. All of the extracts were freshly decocted and analyzed for antioxidant activity by 2, 2-diphenyl-2-picryl hydrazyl (DPPH) radical scavenging assay. Lemongrass extract exhibited the highest inhibition percentage which was $95.90 \%$ followed by curry leaves $(91.99 \%)$, turmeric $(69.01 \%)$ and ginger extracts $(63.41 \%)$. The combination extracts of turmeric-ginger, curry leaves-ginger and curry leaves-turmeric showed the synergistic interaction effects. However, the one to one ratio of lemongrass-curry leaves extracts, lemongrass-turmeric, and lemongrass-ginger extract showed antagonistic interaction effects. In conclusion, most of the plant extracts mixture in this study contributed synergistic interaction in the formulations. This indicates the potential of these mixture to be developed into food product in the future.
\end{abstract}

Keyword: Antioxidant; curry leaves; ginger; lemongrass; turmeric.

\section{Introduction}

Oxygen is a highly reactive molecule that damages living organisms by producing reactive oxygen species. Oxidative stressrelated diseases were caused by the formation of free radicals and the chain reactions [1]. Synthetic antioxidants are seemed to be more effective albeit their unexpected toxicity and side effects. This situation has raise the concern and interest of researchers in investigating the antioxidant properties from natural resources such as plants and herbs.

Most of plants and herbs contain natural antioxidants which can give synergistic interaction effects. However, as the interaction of phytochemical are not inevitable, they might also exert antagonistic, additive and indifferent effect [2]. Synergistic interaction is defined as positive interaction when combining of two or more substances and the mixture show higher mechanism than the sum of the substances. The idea of synergism is practiced by researchers or scientist in the study of antioxidant, antimicrobial, antifungal and formulation of new drug [3]. In contrast, antagonism is the reduced effect when mixed together. Meanwhile, the result shows neither good nor bad is defined as indifferent nor additive is the sum effect of the mixture.

Lemongrass (Cymbopogon citratus), curry leaves (Murrya koenigii), turmeric (Curcuma longa) and ginger (Zingiber officinale) are frequently used as ingredients in food industry. Previous researches proved that these plants contain phytochemicals which contributed to the antioxidant properties [4-7]. However, the evaluation were done individually and rarely in mixtures. Therefore, this present study was conducted to examine the antioxidant properties as well as their interaction effect when mixed together.

\section{Materials and Methods}

\subsection{Plants materials}

Curry leaves and lemongrass were obtained from Taman Waja, Parit Raja, Batu Pahat, Johor. Ginger and turmeric were bought from Agricultural Market Parit Raja. All plant materials were picked fresh and decocted with distilled water. The ratio of plant and distilled 
water was 1:10. The plant samples were boiled until the water was half of the original volume. Then the solution was filtered with Whatman No. 1 filter paper three times to ensure no impurities of the extracts were remained [8].

\subsection{Preparation of the sample}

The filtered samples were collected in aluminum foil covered test tubes prior analysis [9]. Formulations were designed by Design Expert Software ${ }^{\circledR}$ 6.0.4 from State-Ease Inc, United State. A total of 18 formulations of the plants extract were analyzed in the experiment. Table 1 shows the formulation of the corresponding samples.

Table 1 Design layout of the sample formulation

\begin{tabular}{|c|c|c|c|c|}
\hline No & $\begin{array}{c}\text { Lemon } \\
\text { grass } \\
(\mathrm{ml})\end{array}$ & $\begin{array}{c}\text { Curry } \\
\text { Leaves } \\
(\mathrm{ml})\end{array}$ & $\begin{array}{c}\text { Turmeric } \\
(\mathrm{ml})\end{array}$ & $\begin{array}{c}\text { Ginger } \\
(\mathrm{ml})\end{array}$ \\
\hline 1 & 10.00 & 0.00 & 0.00 & 0.00 \\
\hline 2 & 5.00 & 5.00 & 0.00 & 0.00 \\
\hline 3 & 5.00 & 0.00 & 5.00 & 0.00 \\
\hline 4 & 5.00 & 0.00 & 0.00 & 5.00 \\
\hline 5 & 0.00 & 10.00 & 0.00 & 0.00 \\
\hline 6 & 0.00 & 5.00 & 5.00 & 0.00 \\
\hline 7 & 0.00 & 5.00 & 0.00 & 5.00 \\
\hline 8 & 0.00 & 0.00 & 10.00 & 0.00 \\
\hline 9 & 0.00 & 0.00 & 5.00 & 5.00 \\
\hline 10 & 0.00 & 0.00 & 0.00 & 10.00 \\
\hline 11 & 6.25 & 1.25 & 1.25 & 1.25 \\
\hline 12 & 1.25 & 6.25 & 1.25 & 1.25 \\
\hline 13 & 1.25 & 1.25 & 6.25 & 1.25 \\
\hline 14 & 1.25 & 1.25 & 1.25 & 6.25 \\
\hline 15 & 2.50 & 2.50 & 2.50 & 2.50 \\
\hline 16 & 0.00 & 10.00 & 0.00 & 0.00 \\
\hline 17 & 0.00 & 0.00 & 10.00 & 0.00 \\
\hline 18 & 0.00 & 0.00 & 0.00 & 10.00 \\
\hline
\end{tabular}

\subsection{Radical scavenging activity}

The radical scavenging activity was performed according to the previous method of Bondet with slight modification by Miliaukas [10, 11]. The $5.9 \mathrm{mg}$ of 2,2-diphenyl-2-picryl hydrazyl (DPPH) solution was dissolved in $100 \mathrm{ml}$ of methanol. The solution was prepared daily to ease the oxidation of the solution. Three (3) ml of DPPH solution was mixed with $77 \mu \mathrm{l}$ of sample. The samples were then kept in dark for 15 minutes at room temperature. A UV- Vis spectrophotometer was used to evaluate the absorption at $515 \mathrm{~nm}$. The procedure was repeated for three times. The radical scavenging activity was then calculated using the formula:
$\%$ Inhibition $=[(\mathrm{AB}-\mathrm{AA}) / \mathrm{AB}] \mathrm{X} 100$

Where: $\mathrm{AB}-$ absorption of blank sample $(\mathrm{t}=$ 0min); AA- absorption of tested extract solution $(\mathrm{t}=15 \mathrm{~min})$

\subsection{Interaction effect}

The interaction effects of the plant were calculated according to Hugo et al. [12] with slight modification. The predicted values of the response were calculated by combining the percentage of each response of each single plant extract according to the proportion of the mixtures. Thus the predicted inhibition were used to compare with experimental percentage to determine the interaction effects.

\subsection{Statistical analysis}

The statistical analysis was performed using the Design Expert Software ${ }^{\circledR}$ 6.0.4 from State-Ease Inc, United State. Simplex lattice was used to design the formulations. The factor were lemongrass, curry leaves, turmeric root and ginger roots. As the antioxidant assay are expressed in percentages and values. The data were analyzed as one way analysis of variance (ANOVA), surface contours plot and triangular contours diagram. The statistical significant difference was then evaluated with SPSS 16 at value of $p<0.05$ [13].

\section{Result and Discussion}

The results of each individual plants extract are presented in table 2 . Based on the experiment, lemongrass extract showed the highest inhibition followed by curry leaves, turmeric and ginger extracts. The antioxidant activities of the lemongrass and curry leaves extracts was higher when compared to turmeric and ginger extracts as the radical scavenging activities of lemongrass and curry leaves extracts recorded at $95.9 \%$ and $91.99 \%$, respectively. The result was similar with the study of Deepa et al. [14] where aqueous extract of the lemongrass have radical scavenging power than aqueous extract of curry leaves due to the flavonoid content. Turmeric and ginger extracts only gave radical scavenging inhibition of $69.01 \%$ and $63.405 \%$, respectively (Fig. 1). 
Table 2 DPPH radical scavenging activity of single plant extracts according to standard run number

\begin{tabular}{|c|c|}
\hline Formulation & $\begin{array}{c}\text { DPPH radical scavenging } \\
\text { activity }(\%)\end{array}$ \\
\hline 1 & $95.90 \pm 0.39^{\mathrm{a}}$ \\
\hline 5 & $90.64 \pm 0.71^{\mathrm{c}}$ \\
\hline 16 & $93.34 \pm 0.52^{\mathrm{b}}$ \\
\hline 8 & $68.59 \pm 0.14^{\mathrm{i}}$ \\
\hline 17 & $69.42 \pm 0.79^{\mathrm{k}}$ \\
\hline 10 & $63.60 \pm 0.73^{\mathrm{j}}$ \\
\hline 18 & $63.21 \pm 0.61^{\mathrm{j}}$ \\
\hline
\end{tabular}

Values are mean \pm standard deviation $(n=3)$. Values with the same superscript letter within each column are not significant different $(p>0.05)$.

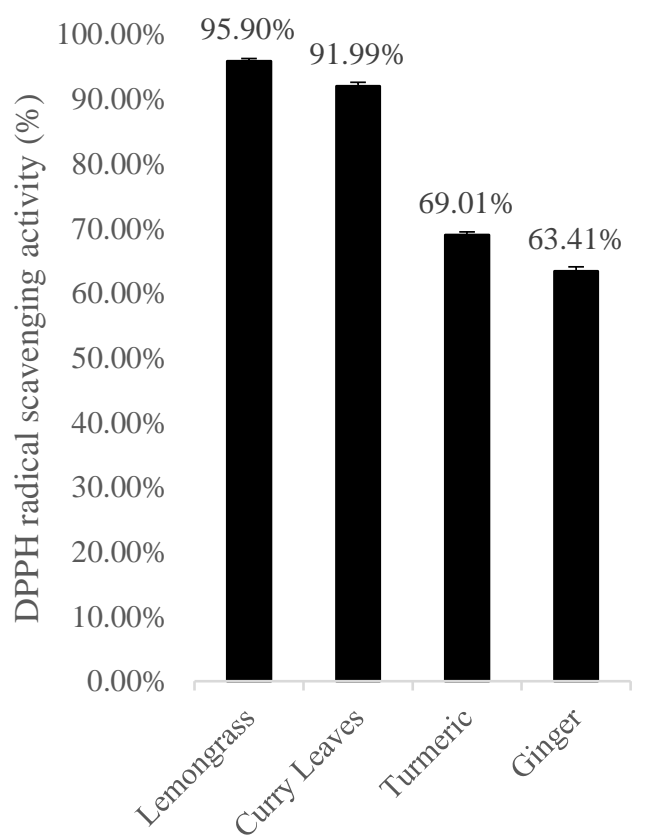

Plant extract

Fig. 1 DPPH radical scavenging activity of lemongrass, curry leaves, turmeric and ginger extracts

However, when the turmeric was mixed with ginger, the DPPH radical scavenging activity values were increase to $93.64 \%$ which indicates the synergistic interaction of the two plant extracts. This result is supported by a study conducted by previous study [8]. The mixture of turmeric-curry leaves has also shown significant synergistic effect. Meanwhile, the combination of turmericlemongrass have shown that there was antagonistic interaction by $3.41 \%$ lower than the predicted value $(82.46 \%)$ (Table 3 and Fig.
2). Previous study showed that turmeric contain of curcumin which soluble in ethanol, alkalis, ketone, acetic acid and chloroform but insoluble in water. In this study, the aqueous extract of turmeric resulted the curcumin fail to exert the antioxidant properties and caused the antagonistic interaction effects [15].

Table 3 DPPH radical scavenging activity of turmeric mixed with other plant extracts

\begin{tabular}{|c|c|c|}
\hline Formulation & $\begin{array}{c}\text { Predicted } \\
\text { value (\%) }\end{array}$ & $\begin{array}{c}\text { DPPH radical } \\
\text { scavenging } \\
\text { activity }(\%)\end{array}$ \\
\hline 3 & $82.46 \pm 0.42$ & $79.05 \pm 0.27^{\mathrm{f}}$ \\
\hline 6 & $80.51 \pm 0.51$ & $94.65 \pm 0^{\mathrm{g}}$ \\
\hline 9 & $66.22 \pm 0.36$ & $93.64 \pm 0.41^{1}$ \\
\hline 13 & $74.55 \pm 0.43$ & $86.24 \pm 0.65^{\mathrm{i}}$ \\
\hline
\end{tabular}

Values are mean \pm standard deviation $(\mathrm{n}=3)$. Values with the same superscript letter within each column are not significant different $(p>0.05)$.

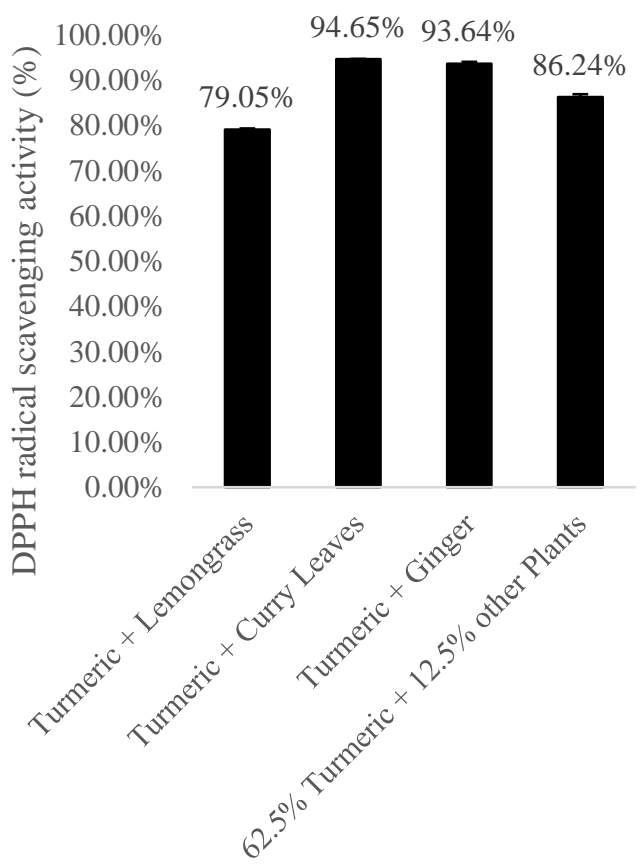

Plant extract

Fig. 2 DPPH radical scavenging activity of turmeric mixed with other plants extract

The ginger mixture had showed a synergistic effect in 1:1 ratio with curry leaves but showed an antagonistic effect in 1:1 ratio with lemongrass extract. Previous study showed that lemongrass, ginger and curry leaves contain of phenolic and flavonoid compounds [16]. Research by Roginsky and 
Lissi [17] reported that DPPH radical are more likely to react with phenolics rather than flavonoids, which contain no OH-groups in Bring as well as with aromatic acids containing only one $\mathrm{OH}$-group. Thus, the antagonistic interaction in this study might cause by the flavonoid compounds in lemongrass contain no $\mathrm{OH}$-groups in B-ring. On the other hand, the combination of $62.5 \%$ of ginger extract with $12.5 \%$ of lemongrass, $12.5 \%$ of curry leaves and $12.5 \%$ of turmeric extracts indicated a synergistic interaction with DPPH radical scavenging activity value of $88.38 \%$ which is higher than a single plant (Table 4 and Fig. 3).

Table 4 DPPH radical scavenging activity of ginger mixed with other plant extracts

\begin{tabular}{|c|c|c|}
\hline Formulation & $\begin{array}{c}\text { Predicted } \\
\text { value (\%) }\end{array}$ & $\begin{array}{c}\text { DPPH radical } \\
\text { scavenging } \\
\text { activity }(\%)\end{array}$ \\
\hline 4 & $79.66 \pm 0.31$ & $77.95 \pm 0.22^{\mathrm{g}}$ \\
\hline 7 & $77.71 \pm 0.44$ & $94.12 \pm 0^{\mathrm{h}}$ \\
\hline 14 & $71.75 \pm 0.35$ & $88.38 \pm 0.95^{\mathrm{j}}$ \\
\hline
\end{tabular}

Values are mean \pm standard deviation $(\mathrm{n}=3)$. Values with the same superscript letter within each column are not significant different $(p>0.05)$.

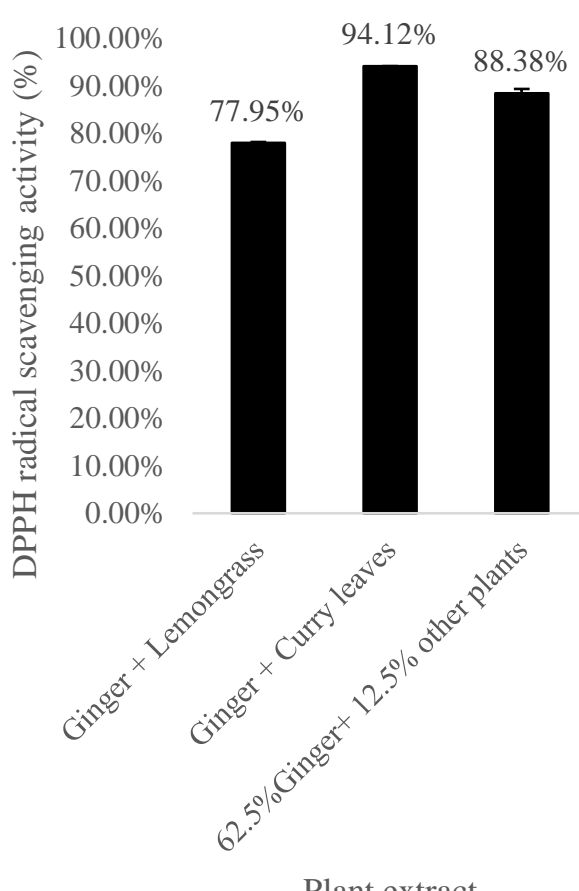

Fig. 3 DPPH radical scavenging activity of ginger mixed with other plants extract.
Table 5 showed the other interaction effects of other plant mixtures. However, the mixture of lemongrass and curry leaves recorded percentages inhibition of $91.14 \%$ which is lower than the predicted values and therefore proven that the mixture has antagonistic effects.

Table 5 DPPH radical scavenging activity of other combinations of plant extract

\begin{tabular}{|c|c|c|}
\hline Formulation & $\begin{array}{c}\text { Predicted Value } \\
(\%)\end{array}$ & DPPH (\%) \\
\hline 2 & $93.95 \pm 0.47$ & $91.14 \pm 2.00^{\mathrm{b}}$ \\
\hline 11 & $88.00 \pm 0.39$ & $93.49 \pm 0.73^{\mathrm{d}}$ \\
\hline 12 & $86.04 \pm 0.49$ & $94.41 \pm 0.82^{\mathrm{e}}$ \\
\hline 15 & $80.08 \pm 0.41$ & $92.07 \pm 0.77^{\mathrm{g}}$ \\
\hline
\end{tabular}

Values are mean \pm standard deviation $(n=3)$. Values with the same superscript letter within each column are not significant different $(p>0.05)$.

\section{Conclusion}

As the conclusion, most of the plant mixtures exhibited synergistic interaction on DPPH radical scavenging assay and three mixtures shows antagonistic interaction effects which were 1:1 mixture of lemongrass-curry leaves, lemongrass-turmeric and lemongrassginger. Hence, the combination should be avoided in future manufacturing to prevent the inverse effect.

\section{Acknowledgements}

The authors are grateful to the lecturer as well as laboratory assistance for the technical support. Acknowledgment goes to Universiti Tun Hussein Onn Malaysia for the facilities and financial support.

\section{References}

[1] Ningappa, M, B, Dinesha, R., Srinivas, L. (2007). "Antioxidant and Free Radical Scavenging Activities Of Polyphenol-Enriched Curry Leaf (Murraya koenigii L.) Extracts" in Food Chemistry, 106(2), pp. 720-728.

[2] Karmegam, N., Karuppusamy, S., Prakash, M., Jayakumar, M., Rajasekar, 
K. (2008). "Antibacterial Potency and Synergistic Effect of Certain Plant Extracts against Food-Borne Diarrheagenic Bacteria" in International Journal of Biomedical and Pharmaceutical Science, 2(2), pp. 8893.

[3] Blesson, J., Saji, C.V., Nivya, R.M., Kumar, R. (2015). "Synergistic Antibacterial Activity of Natural Plant Extracts and Antibiotics against Methicillin Resistant Staphylococcus Aureus (MRSA)" in World Journal of Pharmacy and Pharmaceutical Sciences, 4(3), pp.741-763.

[4] Kemper, K. J. (1999). "Ginger (Zingiber officinale)" in Longwood Herbal Task Force, pp.1-18.

[5] Cheel, J., Theoduloz, C., Rodrguez, J. \& Schmeda, H. G. (2005). "Free Radical Scavengers and Antioxidants from Lemongrass (Cymbopogon citratus (DC.) Stapf.)" in Journal of Agricultural and Food Chemistry, 53(7), pp. 25112517.

[6] Akram, M., Uddini, S., Ahmed, A., Usmanghani, K., Hannan, A., Mohiuddin, E. \& Asif, M. (2010). "Curcuma longa and Curcumin: A Review Article" in Romanian Journal of Biology and Plant Biology, 55, pp. 65-70.

[7] Das, J. E., Bhaumik, U., Raychudhari, R. \& Chakraborty. (2011). "Role of Nutraceutical in Human Health" in Journal of Food Science and Technology, 49, pp. 173-183.

[8] Aida, W.M., Maizura, M., Aminah, A. (2011). "Total Phenolic Content and Antioxidant Activity of Kesum (Polygonum Minus), Ginger (Zingiber officinale) and Turmeric (Curcuma longa) Extract" in International Food Research Journal, 18, pp.529-534.

[9] Padmavathy, S. (2014). "Evaluation of Antioxidant Activity of Gaultheria fragratissima Wall" in Asian Journal of Pharmaceutical Science \& Technology, 4(2), pp. 65-67.

[10] Bondet, V., Williams, B. W., \&Berset, C. (1997). "Kinetics and Mechanisms ofAntioxidant Activity Using The DPPH Free Radical Method" in LWTFood Science and Technology, 30(6), pp. 609- 615 .
[11] Miliauskas, G., Venskutonis, P., \& Van Beek, T. (2004). "Screening of Radical Scavenging Activity of Some Medicinal and Aromatic Plant Extracts" in Food Chemistry, 85(2), pp. 231-237.

[12] Hugo, P.C., Joana, G.G., Rogerio R.S.M., Namiesnik, J, Gorinstein S and Gustavo A.G.A. (2012). "Antioxidant Interactions between Major Phenolic Compounds Found In "Ataulfo" Mango Pulp: Chlorogenic, Gallic, Protocatechuic and Vanillic Acids" in Molecules, 17(11), pp.12657-12664.

[13] Maura, N.L., Mario, S., Donato, P. (2013). "Evaluation of Synergistic Interactions of Antioxidants from Plant Foods by a New Method using Soybean Lipoxygenase" in Journal of Food and Nutrition Research, 52(4), pp. 256-260.

[14] Deepa, G., Aditya, M., Nishtha, K. \& Thankamani, M. (2012). "Comparative Analysis of Phytochemical Profile and Antioxidant Activity of Some Indian Culinary Herbs" in Research Journal of Pharmaceutical, Biological and Chemical Sciences, 3(3), pp. 845-854.

[15] Araújo, C. C., Leon, L. L. (2001). "Biological Activities of Curcuma longa L." in Memórias do Instituto Oswaldo Cruz, 96(5), pp. 723-805.

[16] Mošovská, S., Nováková, D. and Kaliňák, M. (2015) "Antioxidant Activity of Ginger Extract and Identification of its Active Components" in Acta Chimica Slovaca, 8(2), pp. 115-119.

[17] Roginsky, V \& Lissi, E.A. (2005). "Review of Methods to Determine Chain-Breaking Antioxidant Activity in Food" in Food Chemistry, 92(2), pp. 235-254. 